Bazzini, D. G., \& Shaffer, D. R. (1999). Resisting temptation revisited: Devaluation versus enhancement of an attractive suitor by exclusive and nonexclusive daters. Personality and Social Psychology Bulletin, 25(2): 162176. (Feb 1999) Published by Sage (ISSN: 1552-7433) DOI:10.1177/0146167299025002003

\title{
Resisting Temptation Revisited: Devaluation Versus Enhancement of an Attractive Suitor by Exclusive and Nonexclusive Daters
}

Doris G. Bazzini and David R. Shaffer

\begin{abstract}
Individuals committed to exclusive relationships often evaluate attractive, opposite-sex targets less favorably than do less committed individuals. This devaluative distortion of alternatives has been interpreted as relationship maintenance by exclusive daters. Two experiments evaluated an alternative hypothesis: Less committed individuals may more favorably evaluate attractive, other-sex targets because they are seeking a relationship. In Experiment 1, exclusive and nonexclusive daters imagined a scenario in which an attractive stranger showed interest in the participant (high threat/high opportunity) or in his or her best friend (low threat/low opportunity). In Experiment 2, exclusive and nonexclusive daters anticipated interacting with an attractive target who was either available/seeking a relationship (high threat/high opportunity) or unavailable for a relationship (low threat/low opportunity). As predicted, nonexclusive daters evaluated available targets more favorably than unavailable ones, showing clear evidence of relationship-seeking motives. However, exclusive daters showed little evidence of devaluing available targets in the interest of relationship maintenance.
\end{abstract}


Because relationships are one of the most central aspects of our lives (Brehm, 1992), they are often portrayed as valued personal and social resources that we are motivated to protect. According to conservation of resource theory (Hobfoll, Freedy, Lane, \& Gellery, 1990), people experience stress when circumstances threaten or result in the loss of these valued interpersonal resources. Indeed, a variety of behaviors are employed by highly committed individuals seeking to maintain their existing relationships. For example, Dainton and Stafford (1993) found that the most frequently reported maintenance behavior by both married and dating couples was sharing tasks (e.g., partaking together in household activities such as cooking). Other factors that have been proposed to contribute to the maintenance of an ongoing relationship are such strategies as maintaining the belief that a current relationship is superior to other existing relationships (Van Lange \& Rusbult, 1995), affiliating with couples whose relationships are perceived as well functioning (upward comparison), and engaging in accommodating behaviors during conflicts with a partner (Rusbult \& Buunk, 1993).

However, maintaining an existing relationship does not rest exclusively on behaviors pertinent to the relationship itself. Given that individuals involved in a highly committed and satisfying romantic relationship may encounter desirable alternative partners, some relationship-maintenance behaviors are grounded in making involvement with such an alternative as unattractive as possible (Rusbult \& Buunk, 1993). Hence, individuals who are committed to an exclusive relationship should be motivated to actively avoid or perhaps even devalue potential external threats to that relationship (Rusbult, 1983).

Johnson and Rusbult (1989) conducted three complementary studies to test the hypothesis that individuals who are highly committed to a current dating relationship would devalue potential alternative partners, particularly under high-threat conditions (i.e., when the alternative is attractive and available). Results were generally consistent with their hypothesis. More specifically, an initial 7-month longitudinal study demonstrated that the perceived quality of participants. alternatives decreased over time among individuals who stayed in romantic relationships. By contrast, the perceived quality of alternatives increased for individuals who had left the relationship in which they had been involved at the study.s onset. 
A second study used a computer dating paradigm that included a manipulation of threat to an existing relationship by varying the degree of attractiveness of an opposite-sex target person who participants were asked to evaluate. In addition, Johnson and Rusbult (1989) manipulated point of view (either personal or impersonal) for evaluating the target individual. Participants in the personal evaluation condition were asked to make judgments of the target based on how they personally felt about him or her. Furthermore, they were told that if they later decided to participate in a dating service, this information would be used to match them with potential dates. By contrast, participants in the impersonal evaluation condition were asked to make judgments based on how they thought the average university student would rate the target. Unlike the personal evaluators, if they decided to participate in the dating service, their evaluations would not be solicited for later date matching. Because the point of view manipulation actually included an additional and possibly confounding feature (the manipulation of opportunity to date the target), Johnson and Rusbult interpreted these results cautiously. Nonetheless, their second study revealed that participants who were more committed to a current relationship engaged in the greatest amount of alternative devaluation under conditions of higher threat (i.e., the alternative was extremely attractive, and there was a potential opportunity to meet).

Finally, participants in the third study engaged in a role-play simulation in which they placed themselves in the position of an essay protagonist. The protagonist's commitment to and satisfaction with his or her current dating relationship was manipulated, and participants were asked to evaluate potential alternative partners. Results indicated that persons who had placed themselves in the shoes of a highly committed protagonist reported lower attraction to the alternative partners, less desire to date alternatives, and lower general evaluations of alternatives than did those who had placed themselves in the position of a less committed protagonist.

Despite Johnson and Rusbult's (1989) assertion that relationship-maintenance processes should be operative only under conditions of realistic threat to the ongoing relationship, Simpson, Gangestead, and Lerma (1990) extended this research by demonstrating that attractive, opposite-sex targets need not be realistically available to a person to elicit devaluation. That is, individuals involved in exclusive dating relationships perceived young, opposite-sex persons shown in magazine ads as less physi- 
cally and sexually attractive than did other participants who were not currently in an exclusive dating relationship.

Simpson et al. (1990) proposed that the mechanisms fostering relationship maintenance may consist of both perceptual and motivational components. The more subtle of the two may exist in the form of perceptual blinders that effectively insulate the individual from being distracted by a highly attractive alternative (even one who is not attainable). More consciously, however, the individual may actively derogate alternatives who actually pose a realistic threat to an established relationship. This latter, more deliberate mechanism may serve to further shield the current relationship from readily available, real-life challenges to its integrity.

\section{Alternative Devaluation or Alternative Enhancement?}

It could be argued that the less favorable reactions of committed relationship partners to attractive, oppositesex targets may not reflect their relationship-maintenance concerns at all. Past research has generally assumed that highly committed individuals were devaluing alternative relationship partners, with less committed individuals being viewed as objective evaluators. By contrast, it is entirely possible that highly committed relationship partners are the true objective evaluators of target person attractiveness and that less committed participants (or those not currently in a relationship) are bolstering their evaluations of targets, fueled by their desire to establish a satisfactory relationship with an attractive person of the other sex. Indeed, Johnson and Rusbult (1989) acknowledged this rival "bolstering of Attractiveness" hypothesis and concluded that, in the absence of completely impartial ratings of the target stimulus, it was impossible to determine unequivocally whether the committed relationship partners were devaluing stimulus persons (SP) in the interest of relationship maintenance, or rather, the less committed partners were enhancing SP attractiveness in the interest of seeking a relationship.

Interestingly, two studies that examined the impact of viewing erotica on aesthetic judgments appear to contradict the relationship-maintenance hypothesis. Specifically, Kenrick, Gutierres, and Goldberg (1989) found that married men who had viewed Playboy-type centerfolds, as compared to married counterparts who had viewed abstract art, not only rated their stimuli as more aesthetically pleasant but subsequently rated themselves 
less in love with their wives. Unfortunately, there were no evaluations of the Playboy centerfolds by unmarried (or other .less committed.) men, who may indeed have rated such stimuli even more positively than the married participants did. However, the finding that exposure to attractive, opposite-sex targets apparently made married participants less satisfied with their wives hardly seems consistent with the premise that these individuals were especially concerned about protecting their marital relationships from threat.

\section{The Present Research}

The studies discussed heretofore have been predominantly hypothetical in nature, and as such, it might still be argued that such hypothetical scenarios lack genuine involvement on the part of participants. Specifically, more committed, exclusive daters may willingly comply with the experimental instructions to consider the target.s attractiveness without thinking much about any relationship-relevant implications of doing so, and their responses may not accurately reflect how they would feel or what might transpire if faced with a real and compelling temptation. We felt it necessary, however, to replicate these past investigations by conducting a study similar to that of Johnson and Rusbult (1989) and Simpson et al. (1990) but with the inclusion of an appropriate comparison group in order to address the possibility that people who are not in a committed relationship may be bolstering the attractiveness of attractive, opposite-sex stimulus persons.

Specifically, the present research attempted to establish more conclusively whether the differential reactions of committed and less committed relationship partners to attractive individuals of the other sex are best interpreted as reflecting the relationship-maintenance concerns of committed participants or the relationship-seeking motives of their less committed counterparts. Yet, to achieve this aim, one must establish a baseline for evaluating the attractiveness of alluring, opposite-sex individuals.one that is equally objective for both committed and less committed participants. Although it might be argued that no truly objective group of individuals can be obtained for a study such as this, our solution in Experiment 1 was to solicit evaluations of a target person who was clearly interested in someone other than the participant and, thus, posed neither a threat to the relationship of committed individuals nor a relationshipseeking opportunity for less committed individuals. 


\section{EXPERIMENT 1}

Experiment 1 employed a role-playing scenario in which self-reported exclusive (i.e., committed) daters and nonexclusive (less committed) daters imagined encountering an attractive, opposite-sex stranger who displayed obvious interest in either themselves or a best friend of theirs. This latter variable can be construed as a manipulation of threat to an existing relationship or as an opportunity to establish a new relationship. That is, relative to the stranger who is interested in the participant.s friend, a stranger who expresses interest in the participant him- or herself should threaten the existing relationship of an exclusive dater while presenting a golden opportunity for a nonexclusive dater to establish a new alliance.

Here, then, is a scenario that allows for the possibility of determining whether the previous differences between exclusive and nonexclusive daters in ratings of attractive, opposite-sex stimulus persons are due to devaluation of targets by the exclusive daters or to enhancement of targets by the nonexclusive daters. If devaluation were occurring, as implied by Rusbult's relationshipmaintenance theory, then exclusive daters should rate stimulus persons less favorably when they show obvious interest in participants themselves (high threat/high opportunity) than in the participants' friends (low threat/low opportunity). By contrast, if enhancement of targets by nonexclusive (or less committed) individuals explains past findings, then nonexclusive daters should rate a stranger interested in them (high threat/high opportunity) more favorably then a stranger whose interest centers on a friend (low threat/low opportunity). Of course, it is conceivable that both devaluation of attractive SPs by the exclusive individuals and enhancement of these SPs by nonexclusive individuals might co-occur. But even so, we presume that differences in ratings as a function of dating status will be apparent only in the high-threat/opportunity condition, with participants in the low-threat/opportunity condition being a closer approximation to an unbiased baseline for judging the attractiveness of the SP. 


\section{Method}

\section{PARTICIPANTS AND DESIGN OVERVIEW}

Participating for course credit were 98 undergraduate psychology students (49 males and 49 females) at a southern university.

Early in the academic term, participants completed an assessment of their current dating behavior within the context of heterosexual relationships. This instrument used items from the Current Dating Relationship Questionnaire (Johnson \& Rusbult, 1989) to assess participants. current dating statuses and perceived levels of satisfaction with and commitment to their current romantic relationships. If participants were not currently involved in an exclusive dating relationship, they were informed to either answer the dating relationship questionnaire with regard to one of the persons whom they were currently dating or to answer with regard to the last person whom they dated. Participants were classified as either exclusive daters or nonexclusive daters by their responses to the same two items used by Johnson and Rusbult (1989): .Are you currently dating someone?. (yes/no) and .Do you see only each other?. (yes/no). Additionally, to be considered an exclusive dater, participants had to have been dating a partner at least 3months ( $\mathrm{M}$ length of relationship $=16.56$ months for exclusive daters in the current study). This resulted in a total of 48 nonexclusive daters (individuals either not currently in a relationship or not dating a partner exclusively) 1 and 50 exclusive daters, with approximately equal numbers of males and females comprising both groups.

One week later, these exclusive and nonexclusive daters were each exposed to one of two hypothetical scenarios that served as a manipulation of threat to existing relationship/opportunity to establish an alternative relationship. Each scenario required the participant to imagine him- or herself at a restaurant with a best friend. In the high-threat/high-opportunity scenario, an attractive, opposite-sex stranger expressed strong interest in the participant, whereas in the low-threat/low-opportunity scenario, the attractive stranger expressed strong interest in the participant's best friend. Thus, the design was a 2 (gender) $\times 2$ (dating status) $\times 2$ (threat/opportunity) factorial. 


\section{PROCEDURE}

During a pretesting session, participants completed a shortened version of the Current Relationship Questionnaire (Johnson \& Rusbult, 1989), which examined participants. dating status and their commitment to and satisfaction with a current relationship (if one existed).

Relationship measures. The Current Relationship Questionnaire consisted of three general information items, two perceived satisfaction measures, and two items assessing commitment to an existing relationship. The general information items assessed current dating status (married, engaged, living together, dating steadily, dating occasionally, dating casually, not dating), exclusivity of the relationship, and duration of the relationship. If a participant reported that he or she was not currently involved in a romantic relationship, he or she was instructed to respond to the remainder of the questionnaire with reference to his or her most recent relationship.

The items measuring satisfaction with an existing relationship assessed the extent to which participants were satisfied with their relationships and the strength of feelings for their partners. The items measuring commitment to an existing relationship assessed the extent to which participants felt committed to maintaining their relationships and the estimated likelihood that their relationships would end in the near future. All items were assessed on 5-point Likert scales, on which 5 indicated more of an attribute.

In a second session conducted 1 week later by a different experimenter, participants volunteered for a social perception study. They were told that the experiment was designed to assess individuals. reactions to a hypothetical written scenario of the kind that people occasionally face. The scenario was distributed in an unmarked, sealed envelope to ensure that the experimenter was completely blind to experimental conditions. Along with the scenario, participants were given a questionnaire with items that assessed their impressions and evaluations of the target person about whom they had just read. 
Manipulation of threat/opportunity. In the highthreat/high-opportunity scenario, participants read the following paragraphs:

You and your best friend are at Bennigan's one Friday night. From across the room, you spot an extremely attractive member of the opposite sex who had been sitting with friends. About 10 minutes ago, his/her friends left, but you notice that he/she appears to be waiting at his/her table. You get up to use the rest room, telling your friend that you will be back shortly.

As you walk back to the table, your waitress walks up to you and tells you (in confidence) that the person at the other table is her brother/sister. She goes on to say that he or she is very interested in meeting you, but doesn.t want to intrude on you and your friend. When you head back to the table, you tell your friend about the event. In the meantime, the stranger continues to glance over at you, trying to be subtle but obviously very interested. Imagine yourself being in this situation for a few minutes, reading this passage again if necessary. Then complete the attached questionnaire.

In the low-threat/low-opportunity condition, participants read the following paragraphs:

You and your best friend are at Bennigan's one Friday night. From across the room, you spot an extremely attractive member of the opposite sex who had been sitting with friends. About 10 minutes ago, his/her friends left, but you noticed that he/she appears to be waiting at his/her table. Your friend gets up to use the rest room, and tells you he/she will be back shortly. As your friend walks back to the table, your waitress walks up to him/her and tells him/her something (in confidence). When your friend comes back to the table, he/she says that the stranger at the other table is the waitress. sister/brother. The waitress had gone on to say that her brother/sister is interested in meeting him/her but doesn't want to intrude on their interaction. In the meantime, the stranger continues to glance over at your friend, trying to be subtle but obviously very interested. Imagine yourself in this scenario, reading this passage again if necessary. Then complete the attached questionnaire.

Dependent variables. After reading the scenario, participants were asked to indicate their reactions to the interested party on the following 5-point Likert scales. 
Two items, similar to those used by Simpson et al. (1990), assessed the target's superficial physical attributes. One item assessed perceptions of the target's general physical attractiveness, and the other assessed perceptions of how much sex appeal the target possessed.

To assess the target's romantic appeal, participants responded to items similar to those used by Johnson and Rusbult (1989) (i.e., .All things considered, how likely is it that one could have a satisfying relationship with this person? To what extent might one be attracted to this person as a romantic partner? as a prospective date?.).

Following the evaluations of the target, participants once again responded to the four items (included on the Current Relationship Questionnaire of Session 1) that assessed various aspects of (a) participants. satisfaction with their current relationship, (b) commitment to maintaining their current relationship, (c) strength of feelings for their current partner, and (d) the likelihood of their current relationship ending in the near future. (Nonexclusive daters were told to consider one of the persons whom they were currently dating or a person with whom they had had a past relationship when answering the questions.) After completing the questionnaire materials, participants were debriefed, asked to maintain confidentiality, and thanked for their participation.

\section{Results}

\section{OVERVIEW AND PLAN FOR THE ANALYSIS}

To simplify the analyses, evaluations of the hypothetical target individual were broken down into two categories: superficial physical attributes of the target (i.e., general attractiveness and sex appeal) and anticipated satisfaction with the target as a romantic partner. In addition, exclusive daters. perceptions of their (a) commitment to and (b) satisfaction with their current relationship were analyzed in a repeated-measures design, with measures administered before and after exposure to the hypothetical stimulus person.

\section{SUPERFICIAL PHYSICAL ATTRACTIVENESS}

Two assessments of the target's superficial physical attractiveness (i.e., perceived physical attractiveness and perceived sex appeal) were summed into a composite (Cronbach.s alpha $=.60$ ) and submitted to a 2 (gender) $\times 2$ 
(threat/opportunity) $\times 2$ (dating status) ANOVA. The ANOVA produced but one significant outcome, a main effect for threat/opportunity, $F(1,90)=6.31, p<.02$. Specifically, participants in the high-threat/high-opportunity condition rated the target more physically desirable $(M=8.53, S D=1.21)$ than did their counterparts in the low-threat/low-opportunity condition $(\mathrm{M}=7.90$, $\mathrm{SD}=1.39)$.

\section{ASSESSMENTS OF TARGET AS A ROMANTIC PARTNER}

The items most central to our hypothesis were those pertaining directly to participants. impressions of the target as a romantic interest (i.e., . To what extent might one be attracted to this person as a prospective date? a romantic partner?.; .All things considered, how likely is it that one would have a satisfying relationship with this person?.). These three items were summed to form a composite index of the target's attractiveness as a romantic partner (Cronbach's alpha $=.53$ ), and the composite was subjected to a 2 (gender)' 2 (threat/opportunity) 2 (dating status) ANOVA. The ANOVA produced a significant main effect for dating status, $F(1,94)=7.12$, $p<.001$, that was qualified by the two-way interaction between dating status and threat/opportunity, $F(1,94)$ $=4.50, p<.04$, that is shown in Figure 1.2 In examining the figure, it is quite apparent that exclusive daters $(\mathrm{M}=$ $9.77, \mathrm{SD}=1.63)$ and nonexclusive daters $(M=10.00$, $\mathrm{SD}=1.50)$ in the low-threat/low-opportunity condition held similar impressions of the target, $F(1,94)<1$, ns.a finding that implies that exposure to an attractive, othersex SP who is interested in someone else may be a reasonable baseline for evaluating that person's general attractiveness as a romantic partner. By contrast, the effect of dating status was clearly apparent in the highthreat/high-opportunity condition, in which nonexclusive daters $(M=11.13, S D=1.60)$ were much more favorably disposed than were their exclusive dater counterparts $(M=9.25, S D=2.23)$ to targets who were interested in the participants themselves, $F(1,94)=10.92$, $p<.002$. This latter finding essentially replicates past research but does not indicate whether nonexclusive daters, who might be seeking a relationship, were bolstering the desirability of this interested target or, alternatively, exclusive daters were downplaying the target's attractiveness as a romantic partner in the interest of maintaining the integrity of their existing exclusive relationships. 


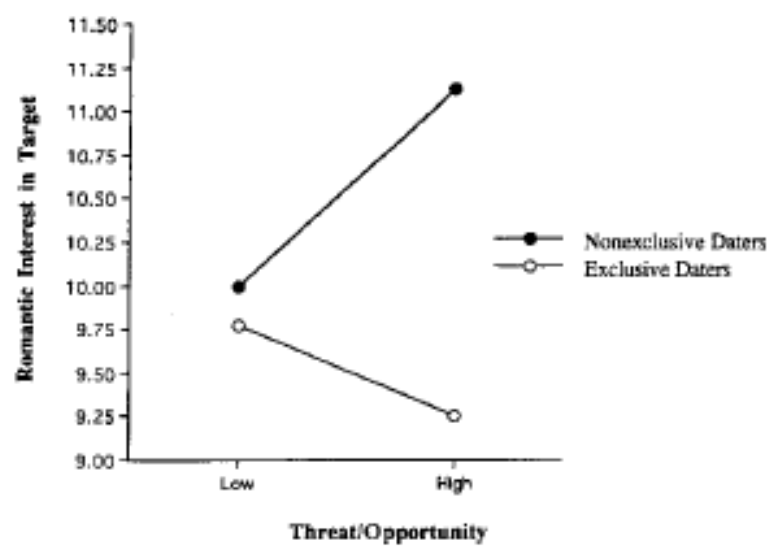

Figure 1 Mean ratings of the target as a romantic interest as a function of thre at/opportunity (low vs. high) and dating status (exclusive vs. nonexclusive).

We next addressed this issue by looking at the simple effects of the threat/opportunity manipulation on exclusive and nonexclusive daters. Nonexclusive daters in the high-threat/high-opportunity condition viewed the target as a much more attractive romantic partner than did their nonexclusive counterparts in the low-threat/lowopportunity condition, $F(1,94)=6.37, p<.02$. Thus, it seems as if nonexclusive daters were bolstering their evaluations of the target when the prospect of establishing a relationship with him or her appeared quite feasible. By contrast, exclusive daters. assessments of the target as a romantic interest did not vary as a function of threat/opportunity, $F(1,94)<1$, ns-a finding that provides little support for the notion that exclusive daters are especially inclined to devalue those attractive individuals who might pose a threat to their existing relationships.

\section{COMMITMENTISATISFACTION WITH CURRENT RELATIONSHIP}

Recall that items were included in both the pre- and postmanipulation questionnaire to determine whether exclusive daters. perceptions of a current romantic partner would be altered as a result of exposure to the target individual. 
The two items that measured commitment to a current dating relationship (i.e., .How committed are you to maintaining your current relationship?. and .How likely is it that your relationship will end in the near future?.) were summed to form pre- and postmanipulation composite commitment indexes (Cronbach's alphas $=.62$ for Time 1 assessment and .85 for Time 2 assessment). (The latter item was reverse-scored to be consistent with the former.) Composite satisfaction scores were also formed for the other two items that assessed satisfaction with a current relationship (i.e., "How satisfied are you with your relationship?" And "How strong would you say your feelings are for your partner?") (Cronbach's alphas $=.74$ for Time 1 and .77 for Time 2). These composites were then submitted to 2 (gender) ' 2 (threat/opportunity) ' 2 (trials) withinparticipants repeated measures ANOVAs to assess whether the perceived commitment and perceived satisfaction of exclusive daters were altered as a function of exposure to the target.

The analyses of the composites failed to reveal significant effects across time, all Fs $(1,46)<2$, ns. In other words, exposure to the target neither enhanced nor undermined exclusive daters. feelings of commitment to (on a 5-point scale, $\mathrm{Ms}=4.39$ and $4.46, \mathrm{SDs}=.84$ and .91 ) or satisfaction with (Ms $=4.43$ and 4.35 , SDs $=.61$ and .82) their current relationship partners across trials.

\section{Discussion}

Taken together, the results of this first experiment were not at all encouraging for the relationship-maintenance interpretations of past research. When asked to evaluate the superficial, physical attributes of an attractive target person (i.e., physical attractiveness and sex appeal), both exclusive and nonexclusive daters indicated that the target who was interested in them personally (high threat/high opportunity) was more attractive than the target who had expressed an interest in their best friend (low threat/low opportunity). Although this is the pattern we would have anticipated of nonexclusive daters who might be seeking a relationship with an available target, it is not consistent with the notion that exclusive daters would seek to maintain or protect their existing relationship by devaluing the attributes of an attractive stimulus person who might pose a threat to that relationship. 
Of course, these assessments of superficial, physical attributes may simply reflect a reciprocity of liking effect (that is, a tendency to be more favorably disposed to others who like us; cf. Condon \& Crano, 1988). Indeed, simply saying that someone is physically attractive is a relatively innocuous assessment that may neither threaten the relationship of an exclusive dater nor indicate any interest whatsoever in establishing a romantic relationship with the target. However, results for the items most pertinent to relationship-maintenance or relationship-seeking concerns (i.e., those assessing desirability of the target as a romantic interest) were more highly informative. Recall that exclusive and nonexclusive daters did not differ in their assessments of lowthreat/low-opportunity targets who were interested in a best friend, whereas exclusive daters were clearly less interested than their nonexclusive counterparts in the high-threat/high-opportunity targets who had expressed an obvious interest in the participants themselves. This latter difference is precisely the kind of evidence that others have interpreted as an indication of devaluative distortion of attractive targets by exclusive daters in the interest of relationship maintenance. Yet, our exclusive daters were no less favorably disposed to the target who expressed an interest in them, thereby posing a hypothetical threat to their exclusive relationship, than in the target who was pursuing a friend and who posed no such threat. In other words, there was no evidence of devaluative distortion of interested and available targets by exclusive daters. By contrast, nonexclusive daters expressed significantly more interest in the target pursuing them than in the target pursuing a friend. They seemed to be bolstering their evaluations of the available target as if they were intrigued by the possibility of establishing a new relationship. So one implication of these data is that committed or exclusive relationship partners from past research may have been the objective evaluators of attractive, opposite-sex stimulus persons, with their less committed (or nonexclusive) counterparts having displayed a facilitative distortion of stimulus persons. attractiveness by which they reflected their interest in (or receptivity to) the prospect of having new relationships.

\section{EXPERIMENT 2}

Unfortunately, one limitation of Experiment 1 and, indeed, of all such experiments pertaining to relationship-maintenance concerns is that manipulations of threat to current relationship/opportunity to establish 
new relationships were indirect or hypothetical, with little acknowledgment that participants in such .as if. simulations may simply tune in norms they consider appropriate under such circumstances. That is, an exclusive relationship partner may easily dismiss the prospect of succumbing to temptation given the socially sanctioned belief that people committed to an exclusive relationship do not cheat on their partner.

Suppose, however, that participants anticipated having close contact with an available, opposite-sex target who had shown some interest in them. This state of affairs (no pun intended) should provide a realistic threat to an exclusive dater and a clear opportunity to a nonexclusive dater in a way not examined heretofore in the literature on relationship-maintenance processes. If relationship-maintenance concerns are operative, exclusive daters expecting to interact with an attractive, available target should describe this individual in less positive terms than would exclusive daters expecting to interact with an equally attractive, unavailable target who poses no threat to their current relationship (Johnson \& Rusbult, 1989). However, if relationship-seeking motives account for the observed differences between exclusive and nonexclusive daters previously cited in the literature, then the possibility of interacting with an available and interested target should activate opportunistic motives among the nonexclusive daters. Hence, these individuals should bolster the attractiveness of the available alternative relative to the target described as romantically unavailable.

Johnson and Rusbult (1989, Study 2) employed a computer dating paradigm that bears some resemblance to our anticipated interaction procedure. Threat to existing relationships was manipulated by varying the attractiveness of the opposite-sex target as well as the implications of participants. evaluations of the target (i.e., high-threat but not low-threat participants were led to believe that if they chose to use an aforementioned dating service, their ratings would be used to match them with prospective dates). As expected, participants more strongly committed to a relationship displayed less favorable evaluations of the target under high threat. the interpretation being that committed participants were inferring that a favorable evaluation might cause them to be paired as a date with this individual. Presumably, their relatively unfavorable evaluations served a relationship-maintenance function by mitigating against this possibility. 
We believe that this explanation is somewhat implausible. For such a scenario to be perceived as threatening, highly committed individuals would have to have seriously entertained the possibility of using the dating service, which itself could serve to undermine rather than maintain the relationship to which they are allegedly committed. A more plausible interpretation of Johnson and Rusbult's (1989, Study 2) findings, we believe, is that the prospect of participating in a dating service presented a significant opportunity for relationship seeking.one to which less committed participants responded by bolstering their evaluations of the target so as to increase the likelihood of being paired with this attractive individual.

Our use of anticipated future interaction with an attractive target was designed to be more direct and definitive in terms of the degree of perceived threat. That is, all participants were initially led to believe that theywould in fact interact with an attractive, opposite-sex target later in the study. In addition, there was a manipulation of the degree of threat/opportunity: Participants were led to believe that the target with whom they would interact was either (a) available and interested in them (high threat/high opportunity) or (b) not available due to involvement in a satisfying exclusive relationship (low threat/low opportunity). Given that Johnson and Rusbult (1989) found that attractiveness of an alternative does indeed make a target more threatening, we chose to hold the attractiveness of our stimulus person constant (and at a high level) across both conditions rather than manipulate it as an additional variable.

Experiment 2 also included a pre- and postmanipulation assessment of the target's superficial attractiveness and sex appeal-an approach that, up until now, has not been used in the relevant relationship-maintenance literature. Essentially, this allowed both exclusive and nonexclusive daters to serve as their own controls to assess any changes in their perceptions of the target as a function of learning that they would interact with himor her. Specifically, one might expect that if exclusive daters perceive an available and attractive target as a potential threat, then learning that the target has romantic interests should lead to even stronger devaluation of that target.s attributes. By contrast, if nonexclusive daters perceive an attractive target as a potential dating opportunity, then knowing that the target is clearly available and romantically interested in him or her should lead to a further bolstering of the target's attributes. 
Of course, it is possible that both devaluation of alternative partners by the exclusive individuals and enhancement of these alternatives by nonexclusive individuals might co-occur. However, differential ratings of the targets should occur only in the high-threat/highopportunity condition. Both exclusive and nonexclusive daters in the low-threat/low-opportunity condition are expected to remain reasonably objective in their assessments of the attractiveness and desirability of the opposite-sex target.

\section{Method}

\section{SUBJECTS AND DESIGN OVERVIEW}

Participants were 104 introductory psychology students (53 males and 51 females) at a southern university who were participating in this investigation in partial fulfillment of a course requirement. All of the participants were heterosexual and Caucasian (due to the fact that all of the stimulus targets were Caucasian and that participants were presented with stimulus targets of the opposite sex). Current dating status and categorization as either an exclusive or nonexclusive were determined by the same criteria used in Experiment 1 . This resulted in a total of 52 nonexclusive daters and 52 exclusive daters (M length of relationship = 18.79 months), with approximately equal numbers of males and females comprising each group.

Participants differing in self-reported dating exclusivity were first exposed to a photograph of an attractive, opposite-sex target and asked to rate this individual on various attractiveness dimensions. In the highthreat/high-opportunity condition, the stimulus person was subsequently portrayed as romantically available and interested in dating the participant. In the lowthreat/low-opportunity condition, the target was portrayed as romantically unavailable with no mention of interest in the participant. Thus, the design was a 2 (gender) ' 2 (threat/opportunity: high vs. low)' 2 (dating status: exclusive vs. nonexclusive dater) factorial.

\section{PROCEDURE}

Participants were run individually. Upon arriving, they were told that the experiment was concerned with how we make judgments of others. In conjunction with the cover story, participants were asked if a Polaroid 
photograph could be taken for the experiment, the purpose of which would be disclosed as the experiment progressed. (All of the participants consented for their picture to be taken.) Participants were then asked to fill out the shortened version of the Current Dating Relationship Questionnaire used in Experiment 1, which classified them according to dating status as well as assessed their commitment to and satisfaction with a current relationship (if one existed).

After the relationship measures were completed, participants were presented with four Polaroid photographs of attractive, opposite-sex individuals. Using an initial target evaluation index, participants were then asked to rate the four individuals in the photographs on a small number of dimensions (e.g., attractiveness and sex appeal) based solely on the photograph. For each gender, two of these four photographs were subsequently used as target persons. Each of these target persons (TP) had been previously rated as relatively attractive by a panel of 20 independent judges (i.e., on 10-point scales, Ms $=7.70$ and 7.60 for male TP;Ms $=7.30$ and 7.70 for females TP). Neither the two male stimulus persons nor the two female stimulus persons differed significantly from each other in attractiveness, Fs $<2$, ns.

After participants rated the four photographs, the experimenter, who was blind as to participants. dating status, randomly and surreptitiously selected one of the two TP photos and led participants to believe that this photo was of another participant currently taking part in the experiment. The experimenter explained that to get a more realistic assessment of how individuals form impressions of others, it was important to look at how two people who do not know each other go about initially getting acquainted. Therefore, the participant and target person would actually interact later in the study; but for now, they would work on some other information to present to this individual.

Then, to facilitate making an acquaintance, the participant was asked to fill out an activities questionnaire. a measure assessing his or her interests, including a question regarding what a typical Saturday night's activities might include. He or she was told that the other participant would be looking at these activity preferences prior to their upcoming interaction. Allegedly, the participant would receive a similar statement from the target describing the target's favorite activities. 


\section{MANIPULATION OF THREAT/OPPORTUNITY}

After completing the questionnaire, an exchange of information occurred. The experimenter presented the participant with the activity questionnaire that had allegedly been filled out by the other participant (i.e., the target person). This information served to manipulate threat/opportunity posed by the target person, which was accomplished as follows.

Low-threat/low-opportunity condition. Under conditions of low threat to an existing relationship (or low opportunity for an individual not currently in an exclusive relationship), the target person described his or her activities as a source of enjoyment for both him- or herself and his or her girlfriend or boyfriend. The target did not mention the participant in his or her statement as follows:

Well, I'm not sure I could say that every Saturday night is typical. Some nights I try to find out if there are any good bands playing around town. is a great place for music, and I really enjoy all types: jazz, progressive, acoustic-you name it. Most times l'll get in touch with some of my close friends, and we'll meet somewhere beforehand for dinner. Other Saturdays I might rent a movie or two. It's nice that my boyfriend/girlfriend enjoys doing the same kinds of things as I do so we can share doing these things.

High-threat/high-opportunity condition. Under conditions of high threat to an existing exclusive relationship (or high opportunity for an individual not currently in an exclusive relationship), the target person described the same activity preferences. However, instead of making reference to a boyfriend/girlfriend, he or she stated a desire to have a significant other to share in such activities. In addition, the hypothetical target addressed the participant and expressed the desire tomeet him or her.

Well, I'm not sure I could say that every Saturday night is typical. Some nights I try to find out if there are any good bands playing around town. is a great place for music, and I really enjoy all types: jazz, progressive, acoustic-you name it. Most times I'll get in touch with some of my close friends, and we'll meet somewhere beforehand for dinner. Other Saturdays I might rent a movie or two. It would be nice to have someone who enjoys doing the same kinds of things as I do to share 
doing these things. Hey, I was wondering if you might want to do something like this some Saturday night?

Following the manipulation of threat/opportunity, the experimenter returned and told the participant that a second set of measures was to be completed prior to interacting with the target. The participant was then given the complete version of the target evaluation questionnaire titled Social Perceptions Inventory. This measure included items assessing target physical attractiveness and sex appeal as well as items assessing his or her evaluation of the target as a romantic interest. Because the participant made two assessments of the target on the two items measuring the target's superficial attractiveness (prior to and after the manipulation of threat/opportunity), Experiment 2 was, in part, a mixed design. On these two dimensions, exclusive and nonexclusive daters in the high-threat/high-opportunity condition could be compared to their counterparts in the low-threat/low-opportunity condition while also functioning as their own controls to assess the impact of the threat/opportunity manipulation.

The Social Perceptions Inventory for this experiment also included a behavioroid measure of self-disclosure to the target. Participants were asked to select 5 topics (from a list of 20) that they would be most willing to discuss in their upcoming face-to-face interaction with the target. These topics had been previously rated on 4-point scales as to their degree of intimacy as discussion probes (e.g., low intimacy: "Places where I would like to live and work"; high intimacy: "Feelings about my past and present of which I am most ashamed") (Jourard \& Jaffe, 1970).

Finally, the same four items used in Experiment 1 were included in the Social Perceptions Inventory, which once again measured satisfaction with and commitment to one's current partner. At the study's conclusion, participants were funnel debriefed and probed for suspicion.[3]

\section{Results and Discussion}

\section{ASSESSMENTS OF TARGETS}

\section{SUPERFICIAL PHYSICAL ATTRACTIVENESS}

Two assessments of the target's superficial physical attractiveness (i.e., perceived physical attractiveness and 
perceived sex appeal) were obtained before and after the manipulation of threat/opportunity and summed into a pre- and postmanipulation composite (Cronbach.s alpha $=.83$ for Time 1 attractiveness assessment and .79 for Time 2 assessment).

The 2 (gender) $\times 2$ (threat/opportunity) $\times 2$ (dating status) $\times 2$ (trials) repeated-measures ANOVA of participants. ratings of the target's physical attractiveness yielded a significant Trials $x$ Threat/Opportunity interaction effect, $F(1,91)=6.51, p=.01$, which is shown in Figure 2. Further analysis of the interaction revealed that only those participants in the high-threat/high-opportunity condition rated the target as more attractive at Time 2 (after hearing of the target's availability and interest in them; $M=8.55, S D=1.57)$ than at Time $1(M=8.00$, $\mathrm{SD}=1.81), F(1,91)=8.12, p<.01$. Under conditions of low threat/low opportunity, participants' ratings of the target's attractiveness did not change over time (Ms =7.86 and 7.76, SDs $=1.67$ and 1.41, for Times 1 and 2 , respectively), $F(1,91)<1$, ns.

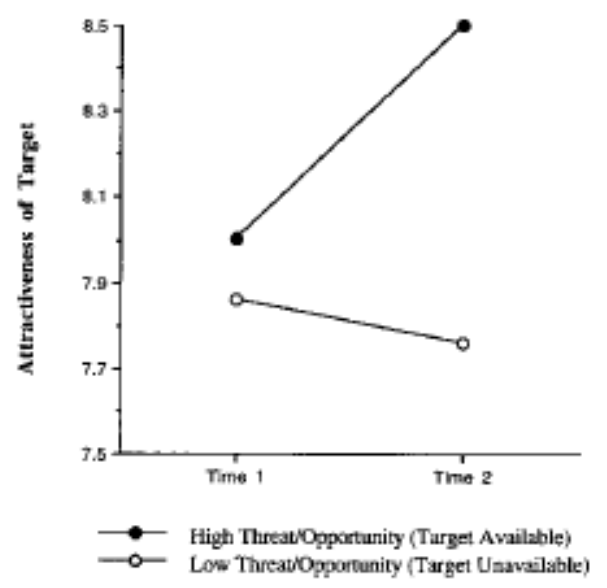

Figure 2 Changes over trials in perceived attractive ness of target as a function of target availability.

Clearly, these findings are consistent with what we anticipated for nonexclusive daters, who were expected to bolster the attractiveness of an available (but not an unavailable) target, fueled by the prospect of establishing a new relationship. However, exclusive daters displayed exactly the same pattern. That is, exclusive daters exposed to an available and interested target also 
viewed the target as more attractive than they had initially, thus displaying no tendency to downplay that person's physical attributes in the interest of relationship maintenance.

\section{EVALUATION OF TARGET AS A ROMANTIC PARTNER}

The items most pertinent to our hypotheses were those assessing participants. impressions of the target as a romantic interest (i.e., "To what extent are you attracted to this person as a prospective date? a romantic partner?" "All things considered, how likely is it that you would have a satisfying relationship with this person?"). Responses to those three romantic interest items were summed (Cronbach's alpha $=.85$ ) and submitted to a 2 (gender) $\times 2$ (threat/opportunity) $\times 2$ (dating status)

ANOVA.

TAB LE 1: Mean Intimacy Scores for Topics of Self-D isclosure as a Function of Dating Status and Threat/Opportunity $(N-97)$

\begin{tabular}{lcc}
\hline & Threat/Opportivaty Maripulation \\
\cline { 2 - 3 } Dating Status & High & Low \\
\hline Exclusive daters & $1.88_{\mathrm{a}}$ & $1.50_{\mathrm{b}}$ \\
Nonexclusive daters & $1.38 \mathrm{~b}$ & $1.47_{\mathrm{b}}$ \\
\hline
\end{tabular}

NOTE: Means with common subscripts are not significantly different at $p<.05$ by the Duncan Range test.

The ANOVA produced but one significant outcome, a main effect of the threat/opportunity manipulation, $F(1,91)=9.54, p<.003$, that was in no way qualified by Participants' dating status (i.e., F for Threat/Opportunity' Dating Status $<1$, ns). Specifically, participants displayed more romantic interest in the interested and available target (high threat/high opportunity, $\mathrm{M}=$ $10.39, \mathrm{SD}=2.60$ ) than in the unavailable target (low threat/low opportunity, $M=8.74, S D=2.80$ ). Clearly, this pattern was what was expected of nonexclusive daters if their prospect of interacting with an available and interested target had activated relationship-seeking motives, thus leading to an enhancement of the perceived romantic potential of the target By contrast, this same enhancement of the available and interested target is hardly consistent with the notion that exclusive daters were striving to protect their current relationship from a real and immediate threat to its integrity. 


\section{WILLINGNESS TO SELF-DISCLOSE TO TARGET}

The scaled intimacy values of the five topics that participants said they would be most willing to discuss with the target in their upcoming acquaintanceship session were averaged to yield a mean disclosure intimacy score for each participant. A subsequent 2 (gender) $\times 2$ (threat/opportunity) $\times 2$ (dating status) ANOVA of these data yielded a main effect for dating status, $F(1,91)$ $=6.94, p<.01$, that was completely qualified by a two-way interaction between threat/opportunity and dating status, $F(1,91)=6.28, p=.01$. As shown in Table 1 , exclusive daters in the high-threat/high-opportunity condition selected more intimate topics for self-disclosure than did their exclusive counterparts under lowthreat/low-opportunity or nonexclusive daters in either threat/opportunity condition. Disclosing intimately to opposite-sex strangers is a ploy often used by people who are interested in building new relationships with those targets (Shaffer, Pegalis, \& Bazzini, 1996). Thus, the willingness of exclusive daters to become relatively intimate with an interested and available target of the other sex hardly seems consistent with the notion that they were highly motivated to protect/maintain their current exclusive relationship.

\section{ASSESSMENTS OF CURRENT RELATIONSHIPS BY EXCLUSIVE DATERS}

Recall that exclusive daters responded twice, before and after being told they would interact with the target, to two items assessing their commitment to their current exclusive relationship and to another two items assessing their satisfaction with that relationship. These items were summed to form composite commitment (Cronbach's alpha $=.62$ ) and composite satisfaction (Cronbach's alpha $=.61)$ indexes. The composites were each then subjected to a 2 (gender) $\times 2$ (threat/opportunity) $\times 2$ (trials) repeated-measures ANOVA to determine whether exclusive daters. perceptions of their current romantic relationship would be altered as a result of their anticipated interaction with readily available or unavailable opposite-sex targets. These exploratory items pertain to the findings of Kenrick et al. (1989), which raise the issue of whether exposure to attractive alternative partners may lead to a devaluation of one's current dating relationship.

Satisfaction with current relationship. The repeatedmeasures ANOVA of the composite satisfaction index 
yielded one outcome - a main effect for gender at both Time 1, F(1, 47) = 7.90, $p=.007$, and Time 2, F(1, 47) = $7.10, p=.001$. Females in exclusive relationships reported higher levels of satisfaction at Time $1(\mathrm{M}=9.36$, $\mathrm{SD}=.64)$ and at Time $2(\mathrm{M}=9.32, \mathrm{SD}=.80)$ than did their male counterparts (Ms $=8.65$ and 8.17, SDs $=1.07$ and 1.95, respectively, for Time 1 and Time 2). The only other outcome to approach significance was the main effect for trials, $F(1,45)=3.45, p<.07$, which reflected the tendency for exclusive daters to report somewhat less satisfaction with their current relationship after learning that they would interact with the attractive, opposite-sex target $(M=8.77, S D=1.56)$ than before $(M=9.02, S D=$ $.93)$, a trend that was in no way qualified by the threat/opportunity manipulation-that is, $F(1,45)<1$, ns for Trials $x$ Threat/Opportunity interaction effect. Here, then, is an outcome reminiscent of the Kenrick et al. (1989) finding that married men exposed to attractive, opposite-sex stimulus persons (even Playboy centerfolds, who were not readily available) rated themselves less in love with their wives.

Commitment to current relationship. The repeated-measures analysis of exclusive daters. feelings of commitment to their current relationships also yielded a marginal trials effect, $F(1,44)=3.10, p<.09$, as well as a significant Trials $x$ Threat/Opportunity interaction effect, $F(1,44)$ $=5.50, p<.05$. Further analysis of the interaction revealed that under high threat/high opportunity (i.e., exposure to an interested and available target), exclusive daters reported weaker feelings of commitment to their current relationship at Time $2(\mathrm{M}=8.79, \mathrm{SD}=1.79)$ than at Time $1(M=9.33, S D=.92), F(1,44)=5.36, p<$ .05. By contrast, exclusive daters in the low-threat/lowopportunity condition reported no changes in perceived commitment to their relationship as a function of anticipating further interaction with an unavailable target. that is, Ms = 8.63 and 8.71, SDs = 1.38 and 1.63, respectively, for Time 1 and Time 2 commitment ratings, $F(1,44)<1$, ns. Thus, when our exclusive daters faced a direct and immediate threat to their current relationship, they appeared to devalue rather than to bolster their feelings of investment in that relationship.[4]

\section{GENERAL DISCUSSION}

Previous research has consistently demonstrated that individuals in highly committed/exclusive and less committed/nonexclusive heterosexual relationships differ in their ratings of young, attractive opposite-sex individu- 
als (Johnson \& Rusbult, 1989; Simpson et al., 1990). Specifically, highly committed/exclusive relationship partners have generally described such targets in less favorable terms (i.e., on superficial physical attributes and personality characteristics) than do less committed/nonexclusive partners. To date, these differences have been taken as evidence for the operation of relationship-maintenance processes among exclusive daters. That is, the assumption has been that committed/exclusive partners devalue alternative targets to protect or preserve a valued, current relationship (the target-derogation hypothesis). Less committed/nonexclusive partners, by contrast, have been looked on as the objective observer control group-people who provide unbiased assessments of target persons' attributes.

However, prior research has failed to rule out an alternative interpretation-namely, that less committed partners, driven by the prospect of establishing exciting new relationships, may display relationship-seeking motives and bolster the attributes of potential dating partners (the target-enhancement hypothesis).

One major objective of the present research was to establish an appropriate baseline against which to compare participants. ratings of attractive, opposite-sex targets who have expressed a clear romantic interest in them (and who should thus represent a strong threat to the integrity of a highly committed/exclusive relationship as well as a clear opportunity for a less committed/nonexclusive dater to establish a new relationship). Our thinking was that such a baseline might involve a target whom participants knew to be interested in or committed to someone other than themselves (i.e., targets in our low-threat/low-opportunity conditions).

The results of Experiment 1 suggested that attempts to create a comparison baseline were successful. That is, exclusive and nonexclusive daters provided comparable assessments of both the superficial physical characteristics and (more important) the romantic potential of the low-threat/low-opportunity target who was interested in their friend. And yet, the experiment clearly replicated past research by demonstrating that nonexclusive daters showed more romantic interest in the available and interested target than did their exclusivedater counterparts. Moreover, the form of the Threat/Opportunity $x$ Dating status interaction that emerged for the highly pertinent romantic attraction index was consistent with what one would expect if nonexclusive daters were seeking a relationship: They 
rated the target who showed interest in them much more favorably than the baseline target who was interested in their friend. By contrast, exclusive daters showed no evidence of devaluing either the superficial physical attributes or the romantic potential of the target interested in them, personally, relative to the baseline target who was interested in their best friend. Such findings are consistent with recent research on what has become popularly known as the .closing time. effect (Madey et al., 1996; Pennebaker et al., 1979)). Madey et al. (1996) examined the effect of being in a romantic relationship on ratings of opposite-sex patrons in a bar at three different time intervals (10:00 p.m., 12:00 a.m., and 1:30 a.m.). They found that individuals not currently involved in a relationship rated opposite-sex patrons to be more attractive as closing time approached; however, no changes in ratings were found for individuals involved in a romantic relationship. To the extent that opposite-sex patrons in a bar might be perceived as viable threats to an exclusive relationship and viable opportunities to those not involved in a relationship, these results are consistent with the target-enhancement rather than target-derogation hypothesis. So, similar to Madey et al., the results of Experiment 1 suggest that past differences in assessments of attractive, opposite-sex targets may well have reflected the relationship-seeking motives of less committed/nonexclusive relationship partners rather than any strong concerns about relationship maintenance on the part of their highly committed/exclusive dater counterparts.

Although the threat to the relationships of our exclusive daters was more straightforward in our first experiment than in past research (e.g., Johnson \& Rusbult, 1989; Simpson et al., 1990), one might nonetheless wonder whether any .as if. simulations can trigger strong relationship-maintenance concerns among highly committed/exclusive relationship partners. Indeed, .as if. simulations (and other similar methodologies) may simply induce highly committed/exclusive relationship partners to quickly access socially sanctioned norms against cheating on relationship partners, which in turn prevent them from thinking too extensively about how they would feel or behave were they to come face to face with an attractive target who was obviously interested in them.

Experiment 2 addressed these concerns by exposing exclusive and nonexclusive daters to a rather direct, contemporaneous threat to existing relationships or opportunity to establish a new relationship. Specifically, 
participants in the high-threat/high-opportunity condition were led to believe that they would soon be interacting with an attractive other-sex target who was available and interested in them. Other participants anticipated interacting with a romantically unavailable control target who posed little threat to an existing relationship or opportunity to establish a new relationship. Indeed, we believe that the low-threat/low-opportunity condition served its intended function as a baseline for target evaluation, because exclusive and nonexclusive daters did not differ in their assessments of the physical attractiveness, the sex appeal, or the romantic potential of these unavailable stimulus persons; in addition, they did not differ in intimacy of topics that they would be willing to discuss face to face with these unavailable targets.

Responses of nonexclusive daters to available targets. As anticipated, our nonexclusive daters in Experiment 2 did respond positively to the opportunity presented to them, viewing the available target as much sexier and more attractive after learning of his or her availability and much more favorably as a romantic interest than the unavailable target. As in Experiment 1, the highthreat/high-opportunity condition did seem to activate relationship-seeking motives among nonexclusive individuals.

Responses of exclusive daters to available targets. Surprisingly, we found that exclusive daters in Experiment 2 also rated interested and available targets more favorably than their unavailable counterparts. Taken alone, such a finding could be interpreted as a simple expectancy-offuture interaction effect. That is, when individuals expect to interact with a potential dating partner (one on whomtheir outcomes are dependent), their evaluations of that person are positively biased (Berscheid, Graziano, Monson, \& Dermer, 1976; see also Darley \& Berscheid, 1967; Tyler \& Sears, 1977). However, such an explanation seems unlikely given that after learning of the target.s availability and interest in them, exclusive daters not only rated this person as more attractive and as generating more romantic interest than the unavailable target but also expressed a greater willingness than nonexclusive daters to discuss intimate topics with the interested and available target-a strategy often used by individuals who are attempting to establish closer relationships with new acquaintances (Shaffer et al., 1996). Finally, exclusive daters actually rated themselves as less committed to their current relationships after learning of their upcoming interaction with the interested/available (but not with the unavailable) target. Taken to- 
gether, these findings imply that our exclusive daters were not especially concerned about relationship maintenance and may have been just as intrigued as nonexclusive daters were by the prospect of establishing a new relationship with an available, interested, and attractive person of the opposite sex.

One could also argue that the apparent unavailability of the low-threat/low-opportunity target was perceived somewhat negatively by both exclusive and nonexclusive daters. That is, participants exposed to the unavailable target may have rated this person lower (rather than those exposed to the available target actually enhancing the target) so as not to interfere with the unavailable SP's existing relationship. Yet, there are several aspects of our findings that speak against this .reluctance-to-horn-in. hypothesis. First, within-subjects ratings of the target before and after learning of target availability/unavailability clearly became more positive for the available target but did not decline for the unavailable target (whom people would allegedly be reluctant to move in on). This in itself suggests enhancement of the available target. Our interpretation is further strengthened, we believe, by the fact that exclusive daters not only rated the available target more positively after learning of his or her availability but, as mentioned earlier, also rated their own current relationship commitment and satisfaction lower. The reluctance-to-horn-in hypothesis would not lead one to expect the latter results, whereas the enhancement interpretation is quite compatible with it.

It should also be noted that our manipulation of target availability may also have appealed to our participants. motivation to form a friendship (not a romantic relationship) with an attractive opposite-sex person. After all, the target in the available condition did express an interest in meeting the participant. However, again our findings seem to call into question such an interpretation given that if the motive of exclusive daters was simply to form a new friendship with the target, itmakes little sense that this friendship motive should have caused participants to become less committed to and somewhat less satisfied with their exclusive relationship partner.

Yet another possible explanation to account for our findings is an individual difference perspective. That is, our effect for dating status might be attributable to personality variables that might differentiate exclusive from nonexclusive daters such as a greater need for intimacy on the part of exclusive daters. However, this 
individual difference interpretation makes main effects predictions and does not easily account for the findings that (a) both exclusive and nonexclusive daters viewed the available (but not the unavailable) stimulus person in favorable terms and (b) that exclusive daters exposed to the available target also showed a decline in current relationship commitment/satisfaction-a finding hardly consistent with the exclusive daters having the greater need for intimacy explanation. Furthermore, Simpson et al. (1990) did measure certain possible mediating variables (e.g., participant attractiveness, selfmonitoring, empathy, and altruism) to determine their respective correlations with dating status. When each was included in the regression analysis, they found that these personality variables neither mediated nor moderated the dating status effect for their dependent variables.

Comparisons with past research. Why were the results of Experiment 2 so inconsistent in implication with previous research, particularly with the work (Johnson \& Rusbult, 1989, Studies 1 \& 2) that guided this research and suggested many of the measures we used as dependent variables? Actual direct comparisons of levels of commitment cannot be made between our participants and those of Johnson and Rusbult (1989), given that mean ratings of relationship commitment were not included in their article. However, one major difference in these two projects concerns the ways in which participants were classified. Johnson and Rusbult studied individuals who were either currently or had recently been in an exclusive relationship, and participants. ratings of commitment to that relationship defined their relationship statuses (allegedly determining how motivated they were to protect the relationship). By contrast, we classified exclusive daters as exclusive without regard to their feelings of commitment to their relationships (which in some analyses were treated as a dependent variable). Thus, one might argue that those of our exclusive daters who initially reported higher levels of commitment to their existing relationships may well have demonstrated relationship-maintenance concerns by devaluing the high-threat, available, and interested target and by showing no undermining of commitment to their relationship as a result of target exposure.

To assess the merits of this reasoning, we classified exclusive daters from each experiment as high or low in relationship commitment based on median splits of their initial (i.e., premanipulation) responses to the item specifically addressing commitment to a current relationship (i.e., . How committed are you to maintaining your 
current relationship?.). Clearly, the resulting means for both the less committed exclusive daters $(M=4.36, S D=$ $.58 ; \mathrm{M}=4.64, \mathrm{SD}=.49$, respectively, for Experiments 1 and 2) and their more committed counterparts ( $M=$ $5.00, S D=0$, respectively, for both experiments) were skewed toward the upper end of the 5-point commitment scale, thus indicating that many of our exclusive daters felt highly committed to their existing relationships. Having classified exclusive daters, we subjected all measures from each experiment to 2 (commitment level) $\times 2$ (gender) $\times 2$ (threat/opportunity) MANOVAs.

Our findings for each experiment revealed that perceived level of commitment to existing exclusive relationships did not affect the results. That is, we found neither a main effect for commitment nor a Commitment' Threat/Opportunity interaction in the overall MANOVAs or in the univariate ANOVAs of our measures of target attractiveness, target romantic potential, willingness to disclose intimately to target (Experiment 2 only), and postmanipulation changes in perceived commitment to/satisfaction with current relationships. Simply stated, highly committed exclusive daters rated target persons no less favorably in either the high-threat or low-threat conditions of either experiment than did their less committed exclusive dater counterparts.Moreover, highly committed exclusive daters of the second experiment were just as inclined as the less committed exclusive daters to feel less committed to their existing relationships after learning they were to interact with the interested and available target.[5] It seems that even our most highly committed exclusive daters showed no meaningful devaluation of the high-threat target, instead displaying a pattern of behavior indicative of their interest in establishing a relationship with this attractive opposite-sex SP.

Is there research concurrent with the notion that a compliment from an attractive stranger might be difficult for a committed dater to resist? Our findings regarding the lack of target derogation on the part of the exclusive daters might be better understood in light of Aronson and Linder.s (1965) gain-loss theory of attraction. According to this theory, positive evaluations from a previously neutral source (a stranger) are more potent than similar evaluations from one's existing close romantic partner. Thus, a person whose liking for us increases over time represents a gain of esteem and, as such, may be particularly intriguing for a person involved in an exclusive relationship. According to Aronson (1995), "Once we have grown certain of the rewarding behavior 
of a person, that person may become less powerful as a source of reward than a stranger." (p. 393). Our exclusive daters may indeed have felt such a gain of esteem after the attractive SP demonstrated interest in getting to know them better and, as a result, rated the target as favorably as the nonexclusive daters and reduced their feeling of commitment/satisfaction toward their romantic partner.

\section{CONCLUSION}

In our opinion, the biggest difference between the present studies and past research centers on the clarity of threats presented to committed relationship partners. Whereas past research posed rather nebulous or implied threats, our exclusive daters knew in no uncertain terms that the high-threat target was interested in them, and they were no doubt aware that a positive response to this interest could challenge the integrity of their existing relationships. Although exclusive daters in our first (scenario) experiment displayed no clear evidence of relationship-maintenance activities in response to such a direct threat, nonexclusive daters clearly bolstered the attractiveness and the romantic potential of this interested and available target. The first experiment, which was the more similar methodologically to past research, implies that the oft-reported differences in evaluations of attractive, opposite-sex stimulus persons probably reflects the relationship-seeking motives of less committed/nonexclusive relationship partners rather than the strong relationship-maintenance concerns of theirmore committed/exclusive dater counterparts.

Indeed, the results of Experiment 2 clearly reinforce this interpretation. When exposed to a real and immediate threat/opportunity, both exclusive and nonexclusive daters indicated a clear interest in the target by favorably evaluating his or her attractiveness, sex appeal, and romantic potential (for themselves). As noted earlier, exclusive daters not only showed as much interest in the high-threat/high-opportunity target as did the nonexclusive daters, but they even reported feeling less committed to their current exclusive relationships after learning of the target's availability and interest in them. In sum, we found not one shred of evidence in our second experiment for the operation of relationshipmaintenance activities among our exclusive daters.

Having drawn this conclusion, we hasten to add that our data in no way establish that the majority of our 
exclusive daters would have actually placed their existing relationships in jeopardy by strongly pursuing the interested and available target had they had close contact with himor her. This is an interesting empirical issue that we, for ethical reasons, felt less than comfortable pursuing. And although the results of our first experiment challenge the empirical bases of conclusions drawn in previous research, we believe that others (e.g., Dainton \& Stafford, 1993; Rusbult, 1983; Rusbult \& Buunk, 1993) are quite correct in asserting that committed relationship partners are generally invested in preserving their existing relationships. Such individuals probably do strap on their perceptual blinders to some extent so that they are not inclined to gawk at attractive members of the opposite sex or to see others. minor flirtations as especially meaningful. Moreover, a strong sense of commitment to a relationship partner probably does cause us to quickly access norms against cheating that, in turn, may help us to avoid situations (e.g., attending parties unescorted) in which we might encounter threats to that commitment. A caveat to consider, however, is that our exclusive daters, similar to those of Johnson and Rusbult (1989) and Simpson et al. (1990), were in college dating relationships. Because our participants were not, in fact, married (that is, more structurally committed to a partner), one might argue that in our high-threat/high-opportunity condition, the level of external threat exceeded participants. level of commitment to their relationship.[6] Nevertheless, the rather obvious interest our exclusive daters displayed toward attractive and available targets in Experiment 2 leads us to an additional conclusion worth exploring further in future research: Even the most committed relationship partners (a) may be sorely tempted and (b) are likely to underestimate in .as if. simulations their ability to dismiss immediate and potentially exciting challenges to the integrity of their existing relationships by attractive suitors who actively initiate such challenges. 


\section{NOTES}

1. Following the logic of Simpson, Gangstead, and Lerma (1990), these two groups of individuals were deemed similar given that individuals who were neither dating nor exclusively committed to one relationship should not interpret the presence of an available alternative dating partner as a threat.

2. These same significant outcomes emerged from a $2 \times 2 \times 2$ MANOVA of the three romantic interest items and from univariate ANOVAs of two of the three items.

3. Great lengths were taken by the experimenter to avoid suspiciousness on the part of participants. During the course of the study, the experimenter kept making reference to checking on the other participant in the experiment. The experimenter would go into another room where the alleged target was taking part in the study and conduct part of a conversation with the target outside of the door of the room where the participant was located. The funnel-type debriefing revealed that participants believed the impression-formation cover story with which they were provided, and no one guessed the hypothesis or indicated that they believed this project to be a dating study. Only 5 participants gave any indication at any point during the debriefing that they had doubted the presence of the target in the next room. These participants were subsequently replaced and their data discarded.

4. Of course, this conclusion rests on the assumption that the decline in commitment displayed by exclusive daters in the highthreat/high-opportunity condition is not merely a regression artifact. As a check on this possibility, 50 additional exclusive daters, whose self-reported initial commitments to their relationships were rather extreme (T1 commitment mean $=9.12)$, spent approximately 20 minutes completing filler tasks (which did not involve opposite-sex SP) prior to rerating their satisfaction with and commitment to their exclusive relationships. Repeated-measures ANOVAs of these satisfaction and commitment indexes yielded no effects for trials on either measure (T2 commitment mean= 9.28) Fs $<1.00$, ns, thus implying that declines in satisfaction/commitment shown by our experimental participants were reactions to target exposure rather than mere regression artifacts.

5. Detailed summaries of these commitment analyses are available on request from the first author.

6. We wish to thank John Lydon for this insight. 


\section{REFERENCES}

Aronson, E. (1995). The social animal. New York: W. H. Freeman.

Aronson, E., \& Linder, D. (1965). Gain and loss of esteem as determinants of interpersonal attractiveness. Journal of Experimental and Social Psychology, 1, 156-171.

Berscheid, E., Graziano, W., Monson, T., \& Dermer, M. (1976). Outcome dependency: Attention, attribution, \& attraction. Journal of Personality and Social Psychology, 34, 978-989.

Brehm, S. S. (1992). Intimate relationships. New York: McGraw-Hill. Condon, J. W., \& Crano, W. D. (1988). Inferred evaluation and the relation between attitude similarity and interpersonal attraction. Journal of Personality and Social Psychology, 54, 789-797.

Dainton, M., \& Stafford, L. (1993). Routine maintenance behaviors: A comparison of relationship type, partner similarity and sex differences. Journal of Social and Personal Relationships, 10, 225-271.

Darley, J.M., \& Berscheid, E. (1967). Increased liking as a result of the anticipation of personal contact. Human Relations, 20, 29-39.

Hobfoll, S. E., Freedy, J., Lane, C., \& Gellery, P. (1990). Conservation of social resources: Social support resource theory. Journal of Social and Personal Relationships, 7, 465-478.

Johnson, D. J., \& Rusbult, C. E. (1989). Resisting temptation: Devaluation of alternative partners as a means of maintaining commitmentin close relationships. Journal of Personality and Social Psychology, $57,967-980$.

Jourard, S. M., \& Jaffe, P. E. (1970). Influence of an interviewer's disclosure on the self-disclosing behavior of interviewees. Journal of Counseling Psychology, 17, 252-257.

Kenrick, D. T., Gutierres, S. E., \& Goldberg, L. L. (1989). Influence of popular erotica on judgements of strangers and mates. Journal of Experimental Social Psychology, 25, 159-167.

Madey, S. F., Simo, M., Dillworth, D., Kemper, D., Toczynski, A., \& Perella, A. (1996). They do get more attractive at closing time, but only when you are not in a relationship. Basic and Applied Social Psychology, 18, 387-393.

Pennebaker, J. W., Dyer, M. S., Caulkins, R. S., Litowitz, D. L., Ackerman, P. L., Anderson, D. B., \&McGraw, K.M. (1979). Don't the girls get prettier at closing time: A country and western application to psychology. Personality and Social Psychology Bulletin, 5, 122-125. Rusbult, C. E. (1983). Commitment and satisfaction in romantic asso- 
ciations: A test of the investment model. Journal of Experimental Social Psychology, 16, 172-186.

Rusbult, C. E., \& Buunk, B. P. (1993). Commitment processes in close relationships: An interdependence analysis. Journal of Social and Personal Relationships, 10, 175-204.

Shaffer, D. R., Pegalis, L., \& Bazzini, D. (1996). When boy meets girl (revisited):Gender, gender-role orientation, and prospect of future interaction as determinants of self-disclosure among same-and opposite-sex acquaintances. Personality and Social Psychology Bulletin, 22, 495-506.

Simpson, J. A., Gangestead, S.W., \& Lerma, M. (1990). Perceptions of physical attractiveness: Mechanisms involved in the maintenance of romantic relationships. Journal of Personality and Social Psychology, 59, 1192-1201.

Tyler, T. R., \& Sears, D. O. (1977). Coming to like obnoxious people when wemust live with them. Journal of Personality and Social Psychology, 35, 200-211.

Van Lange, P.A.M., \& Rusbult, C. E. (1995). My relationship is better than.and not as bad as.yours is: The perception of superiority in close relationships. Personality and Social Psychology Bulletin, 21, 32-44. 